\title{
Synthesis and electrochemical properties of $\mathrm{InVO}_{4}$ nanotube arrays
}

\author{
Ying Wang and Guozhong Cao* \\ Received 23rd May 2006, Accepted 29th November 2006 \\ First published as an Advance Article on the web 11th December 2006 \\ DOI: $10.1039 / \mathrm{b} 607268 \mathrm{~b}$
}

This paper reports an experimental study on the synthesis and electrochemical properties of $\mathrm{InVO}_{4}$ nanotube arrays fabricated by capillary-enforced sol-filling in templates in combination with solvent-evaporation induced deposition. $\mathrm{InVO}_{4}$ sol was synthesized using the sol-gel route from vanadium oxoisopropoxide and indium nitrate with ethanol as the solvent. Nanotube arrays of $\mathrm{InVO}_{4}$ were prepared by filling the sol into pores of polycarbonate membranes and pyrolyzing through sintering. Another type of $\mathrm{InVO}_{4}$ nanotube array $\left(\mathrm{InVO}_{4}-\mathrm{acac}\right)$ was obtained from the sol with the addition of acetyl acetone (acac). For comparison purposes, $\mathrm{InVO}_{4}$ films were prepared by drop casting from the same $\mathrm{InVO}_{4}$ sol. Films and the two types of nanotube array of $\mathrm{InVO}_{4}$ annealed at $500{ }^{\circ} \mathrm{C}$ consisted of mixed monoclinic $\left(\mathrm{InVO}_{4}-\mathrm{I}\right)$ and orthorhombic $\left(\mathrm{InVO}_{4}{ }^{-}\right.$ III) phases. Scanning electron microscopy (SEM) characterization indicated that the nanotubes were aligned perpendicular to the substrate surface with an outer diameter of $\sim 200 \mathrm{~nm}$ for short $\mathrm{InVO}_{4}$ nanotubes and $\sim 170 \mathrm{~nm}$ for long $\mathrm{InVO}_{4}$-acac nanotubes. Chronopotentiometry results revealed that the $\mathrm{InVO}_{4}$-acac nanotube array has the highest charge capacity $\left(790 \mathrm{mAh} \mathrm{g}^{-1}\right)$, followed by the $\mathrm{InVO}_{4}$ nanotube array $\left(600 \mathrm{mAh} \mathrm{g}^{-1}\right)$ then the $\mathrm{InVO}_{4}$ film $\left(290 \mathrm{mAh} \mathrm{g}^{-1}\right)$. Such enhanced lithium-ion intercalation properties were ascribed to the large surface area and short diffusion distance offered by nanostructures and amorphisation caused by acetyl acetone in the case of $\mathrm{InVO}_{4}$-acac nanotube arrays.

\section{Introduction}

Orthovanadate compounds with the general formula $\mathrm{M}^{3+} \mathrm{VO}_{4}$ $\left(\mathrm{M}^{3+}=\mathrm{In}, \mathrm{Fe}, \mathrm{Cr}, \mathrm{Al}\right.$, and rare earths) have aroused much interest due to their lithium ion intercalation properties. ${ }^{1-5}$ Among them, $\mathrm{InVO}_{4}$ is particularly interesting because of its high intercalation capacity and good cyclability, and is thus a promising candidate for anode materials in lithium secondary batteries. ${ }^{1}$ For example, amorphous $\mathrm{InVO}_{4} \cdot 2.3 \mathrm{H}_{2} \mathrm{O}$ powders exhibit a high capacity of $900 \mathrm{mAh} \mathrm{g}^{-1}$. Two common phases of $\mathrm{InVO}_{4}$ are $\mathrm{InVO}_{4}$-III (orthorhombic) and $\mathrm{InVO}_{4}$-I (monoclinic). The structure of orthorhombic $\mathrm{InVO}_{4}$ consists of $\mathrm{VO}_{4}$ tetrahedra that form corner-shared chains and $\mathrm{InO}_{6}$ octahedra linked through corners. ${ }^{6}$ In the structure of monoclinic $\mathrm{InVO}_{4}$, there are $\mathrm{In}_{4} \mathrm{O}_{16}$ groups formed by four edge-shared $\mathrm{InO}_{6}$ tetrahedra and these groups are connected to each other by $\mathrm{VO}_{4}$ tetrahedra. ${ }^{6}$ Both phases of $\mathrm{InVO}_{4}$ have open structures which facilitate lithium ion intercalation. The orthorhombic phase can be prepared via high-temperature solid-state reactions from $\mathrm{In}_{2} \mathrm{O}_{5}$ and $\mathrm{V}_{2} \mathrm{O}_{5}$ at $1000{ }^{\circ} \mathrm{C}{ }^{7}$ A low-temperature precipitation route was developed based on the aqueous solution of $\mathrm{InCl}_{3}$ and $\mathrm{NH}_{4} \mathrm{VO}_{3} .{ }^{8}$ Heating of the precipitate at $550{ }^{\circ} \mathrm{C}$ results in the monoclinic phase, while further heating above $700{ }^{\circ} \mathrm{C}$ leads to the orthorhombic phase. Furthermore, a low-temperature dissolution-reprecipitation method was recently developed based on sol-gel chemistry. ${ }^{9}$ In this method, indium nitrate is mixed with vanadic acid or vanadium pentoxide sol. Four to six hours' stirring and

Department of Materials Science and Engineering, University of Washington, Seattle, WA, 98195, USA.

E-mail:gzcao@u.washington.edu heating of the resultant precipitate at $400{ }^{\circ} \mathrm{C}$ form orthorhombic $\mathrm{InVO}_{4}$, whereas a few minutes' stirring of the mixture and heating of the resultant precipitates at $520{ }^{\circ} \mathrm{C}$ give rise to monoclinic $\mathrm{InVO}_{4}$. This dissolution-reprecipitation process can be applied to synthesizing a large variety of monovalent, divalent and trivalent vanadates. ${ }^{10}$ Although all the above methods facilitate the synthesis of pure and different phases of $\mathrm{InVO}_{4}$, the products are in powder form. The electrochemical properties of $\mathrm{InVO}_{4}$ powders have been thoroughly studied by Denis et al. ${ }^{1}$ It was found that amorphous $\mathrm{InVO}_{4} \cdot 2.3 \mathrm{H}_{2} \mathrm{O}$ delivers a very high initial capacity of $900 \mathrm{mAh} \mathrm{g}^{-1}$ and a lower capacity of $700 \mathrm{mAh} \mathrm{g}^{-1}$ after 14 cycles. To make thin films of $\mathrm{InVO}_{4}$, a sol-gel route based on vanadium oxoisopropoxide and indium nitrate has been utilized in combination with dip-coating. ${ }^{11}$ Addition of acetyl acetone (acac) results in a more stable sol and the resultant $\mathrm{InVO}_{4}$ dip-coated film shows lower crystallinity in comparison with those films obtained from the same sol without acetyl acetone and sintered at the same temperature. ${ }^{12}$ The electrochemical and electrochromic properties of the $\mathrm{InVO}_{4}$ films obtained from the solgel route have been investigated. ${ }^{12}$ Compared to films of the pure orthorhombic phase, or a mixed monoclinic and orthorhombic phase, $\mathrm{InVO}_{4}$-acac films exhibit the highest capacity (between 30 and $40 \mathrm{mC} \mathrm{cm}^{-2}$ ), and their electrochemical stability is more than 1000 cycles. This alcoholic sol-gel route has the advantage of providing clear and homogenous sols which give rise to highly transparent films; however, the resultant films consist of mixed phases if sintered at temperatures lower than $600{ }^{\circ} \mathrm{C}$, although the monoclinic and orthorhombic phases of $\mathrm{InVO}_{4}$ have similar electrochemical and electrochromic properties. 
Nanomaterials are attracting great interest for electrochemical energy storage, due to their high surface area and short diffusion distance. ${ }^{13,14}$ Nanostructured $\mathrm{InVO}_{4}$ has not been made yet. In this paper we aim to prepare $\mathrm{InVO}_{4}$ nanotube arrays using a template synthesis method and to compare their electrochemical properties with plain thin films of $\mathrm{InVO}_{4}$. Template synthesis is a general method for preparing ordered arrays of nanostructures with nanorods/ nanotubes/nanocables protruding from the underlying current collector. ${ }^{15}$ Patrissi and Martin, and Cao et al., have investigated the electrochemical properties of $\mathrm{V}_{2} \mathrm{O}_{5}$ nanorod arrays made by depositing vanadium pentoxide sol within pores of polycarbonate (PC) membranes, and reported that nanorod arrays achieved 4 times the capacity of a thin-film electrode at high discharge rate. ${ }^{16-18}$ Our group have further prepared various nanostructures of vanadium pentoxide, including single-crystal $\mathrm{V}_{2} \mathrm{O}_{5}$ nanorod arrays, ${ }^{19-21} \mathrm{~V}_{2} \mathrm{O}_{5} \cdot n \mathrm{H}_{2} \mathrm{O}$ nanotube arrays ${ }^{22}$ and $\mathrm{Ni}-\mathrm{V}_{2} \mathrm{O}_{5} \cdot n \mathrm{H}_{2} \mathrm{O}$ core-shell nanocable arrays, ${ }^{23}$ which have all demonstrated excellent electrochemical or electrochromic properties. The fabrication of such nanostructures has been accomplished using template-based growth by sol electrophoretic deposition ${ }^{24-30}$ and electrochemical deposition. ${ }^{24}$

\section{Experimental}

$\mathrm{InVO}_{4}$ sol was prepared via the sol-gel processing method. $0.782 \mathrm{~g} \mathrm{In}\left(\mathrm{NO}_{3}\right)_{3} \cdot 5 \mathrm{H}_{2} \mathrm{O}$ (Aldrich) was first dissolved into $10 \mathrm{ml}$ absolute ethanol (AAPER), based on a method reported on the literature. ${ }^{12} 0.472 \mathrm{ml}$ Vanadium oxoisopropoxide (Aldrich) was then added to this solution in a molar ratio $\mathrm{In}: \mathrm{V}=1: 1$. The resultant $\mathrm{InVO}_{4}$ sol had a concentration of $0.2 \mathrm{M}$ and was bright orange in color. This sol was stirred for 1 hour prior to template synthesis. Acetyl acetone (acac; $1 \mathrm{ml}$ ) was added to $5 \mathrm{ml} \mathrm{InVO}_{4}$ sol to prolong the stability of the sol. This $\mathrm{InVO}_{4}$ acac sol was dark red in color and was stirred for 0.5 hour prior to template synthesis. Nanotube arrays of $\mathrm{InVO}_{4}$ and $\mathrm{InVO}_{4}-$ acac were grown in polycarbonate templates by means of capillary force induced filling. The templates used were radiation track-etched hydrophilic polycarbonate membranes (Millipore Isopore) with pore diameters of $200 \mathrm{~nm}$ and thicknesses of $10 \mu \mathrm{m}$. Conductive tin doped indium oxide (ITO) substrates were boiled in water for a few hours to ensure a hydrophilic surface. $10 \mu \mathrm{InVO}_{4}$ sol was dropped on the surface of the ITO substrate, and a PC template was gently placed on the top of the sol for $4 \mathrm{~h}$ at room temperature. The samples on ITO substrates were then heated at $110{ }^{\circ} \mathrm{C}$ for $5 \mathrm{~h}$ in air and fired at $500{ }^{\circ} \mathrm{C}$ for $1 \mathrm{~h}$ to remove the PC membrane through pyrolysis and oxidation as well as to densify the $\mathrm{InVO}_{4}$ nanotube arrays. InVO $\mathrm{V}_{4}$-acac nanotube arrays were prepared with the same procedure from $\mathrm{InVO}_{4}-\mathrm{acac}$ sol. For comparison purposes, $\mathrm{InVO}_{4}$ films were prepared by a simple drop casting method. $10 \mu \mathrm{InVO}_{4}$ sol was dropped on the ITO substrate and followed the same heating procedure as the nanotube array samples.

The crystalline phases of $\mathrm{InVO}_{4}$ nanotube arrays and films were analyzed by X-ray diffraction (XRD) using a Philips PW 1820 diffractometer with $\mathrm{CuK} \alpha$ radiation operated at $40 \mathrm{kV}$ and $20 \mathrm{~mA}$. Scanning electron microscopy (SEM, JEOL JSM
5200) was used to examine the morphology of the nanotube arrays. The electrochemical properties of $\mathrm{InVO}_{4}$ nanotube arrays and films were investigated by using a three-electrode cell with a platinum counter electrode and a silver wire in $0.1 \mathrm{M}$ $\mathrm{AgNO}_{3}$-ethanol solution $\left(\mathrm{Ag} / \mathrm{Ag}^{+}\right)$as the reference electrode. A 1 M solution of lithium perchlorate $(99.99 \%$, Alfa Aesar) in propylene carbonate $(99 \%$, Aldrich) was used as the electrolyte. Cyclic voltammetric (CV) measurements were carried out between the potential limits of 0.4 and $-2.8 \mathrm{~V}$ versus $\mathrm{Ag} / \mathrm{Ag}^{+}$ using a scan rate of $10 \mathrm{mV} \mathrm{s}^{-1}$. The chronopotentiometric (CP) measurements were carried out at various specific currents. Unless otherwise specified, all values reported in this paper are based on the mass of applied material. The mass of material was directly calculated from the applied volume $(10 \mu \mathrm{l})$ and the concentration of the sol that converted to the nanotube arrays or the films $\left(0.2 \mathrm{M}\right.$ for $\mathrm{InVO}_{4}$ nanotube arrays and films and $0.167 \mathrm{M}$ for $\mathrm{InVO}_{4}-$ acac nanotube arrays).

\section{Results and discussion}

Fig. 1 presents SEM images of $\mathrm{InVO}_{4}$ nanotube arrays and $\mathrm{InVO}_{4}-\mathrm{acac}$ nanotube arrays, respectively. To ensure the film has the same geometrical area as the nanotube arrays, the film is prepared by a two-step drop-casting method and a porous film resulted after annealing. In magnified SEM images Fig. 1(b) and (d) aligned nanotubes with open ends are observed clearly with an average outer diameter of $\sim 200 \mathrm{~nm}$ for $\mathrm{InVO}_{4}$ nanotubes and $\sim 170 \mathrm{~nm}$ for $\mathrm{InVO}_{4}$-acac nanotubes. $\mathrm{InVO}_{4}$ nanotubes are shorter than $\mathrm{InVO}_{4}$-acac nanotubes, possibly because ethanol (solvent used in making the $\mathrm{InVO}_{4} \mathrm{sol}$ ) has a high volatility while the addition of acetyl acetone (acac) into the sol reduces the volatility of the solvent. We have separately investigated $\mathrm{InVO}_{4}$ nanostructures prepared from a sol using isopropanol as the solvent. The nanostructures turned out to be nanotubes mixed with some nanorods, possibly due to the lower volatility of isopropanol. It should be noted that beneath the $\mathrm{InVO}_{4}$ nanotube arrays is an $\mathrm{InVO}_{4}$ film resulting from the capillary-enforced method by placing the PC membrane on the top of the sol. The shorter $\mathrm{InVO}_{4}$ nanotubes adhere strongly with the $\mathrm{InVO}_{4}$ film at the bottom and form a continuous nanotube film as shown in Fig. 1(a), while the longer $\mathrm{InVO}_{4}$-acac nanotubes cluster together as shown in Fig. 1(c) and have more lateral shrinkage resulting in the smaller diameter of nanotubes.

Capillary-enforced sol-filling in templates in combination with solvent-evaporation-induced deposition has been demonstrated to be an efficient approach for the synthesis of composite nanorod arrays (Fig. 2). Although many elegant techniques such as template-based electrochemical/electrophoretic deposition have been developed for the synthesis of ordered nanostructures, ${ }^{14}$ they can not be used for growing nanostructures of complex oxides, if the sol is not stable under an electric field as in the case of $\mathrm{InVO}_{4}$ sol, or consists of nanoparticles of two or more distinct phases such as the $\mathrm{V}_{2} \mathrm{O}_{5^{-}}$ $\mathrm{TiO}_{2}$ system. ${ }^{32}$ Another advantage is the excellent adhesion of grown nanorod and nanotube arrays on the substrate beneath, because a film of the same material is formed simultaneously between the substrate and the nanorods and nanotubes. Its mechanism is similar to that of slip-casting. ${ }^{31}$ The $\mathrm{InVO}_{4}$ and 

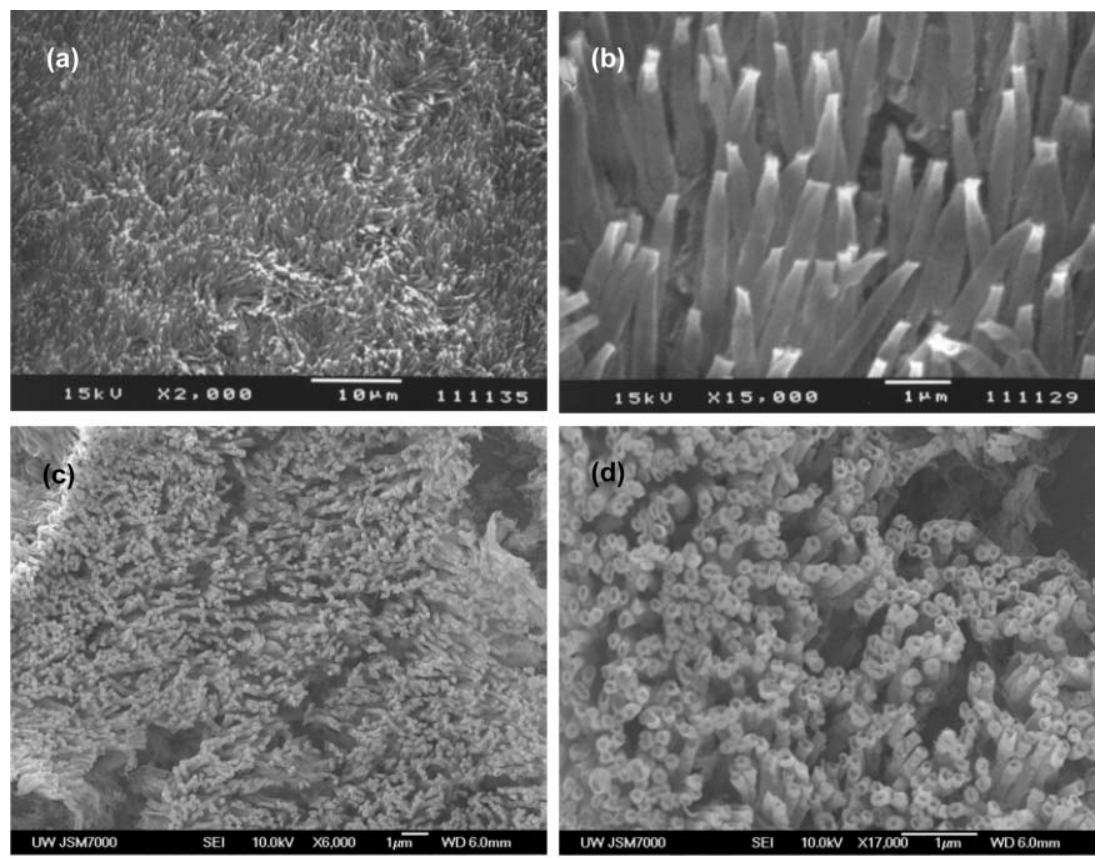

Fig. 1 SEM images of (a) $\mathrm{InVO}_{4}$ nanotube array, (b) magnified view of $\mathrm{InVO}_{4}$ nanotube array, (c) $\mathrm{InVO}_{4}$-acac nanotube array and (d) magnified view of $\mathrm{InVO}_{4}$-acac nanotube array.

$\mathrm{InVO}_{4}$-acac nanotubes were grown by sol filling into PC template pores with capillary force. The sol was drawn up into and filled up the pores of the PC membrane. Air in the pores and the vapor from the sol were evaporated from the top surface of the PC template. Although the exact mechanism for the formation of nanotubes inside the pore channels of PC membranes is not known to us, a possible path for the deposition of solid $\mathrm{InVO}_{4}$ is proposed below. As the solvent evaporates from the surface and the concentration is enriched at the top of the pores, precipitation or gelation occurs first at the top of the pores on the PC membrane surface exposed to the air, and subsequently proceeds downwards along the wall of the entire pores. A typical sol consists of nanosized particles or nanoclusters homogeneously dispersed in an electrolyte solution. Such nanoclusters develop surface charges and form a double layer, and can respond to an externally applied electric field or other nanoclusters. When the surface of a PC membrane is brought into contact with a sol, surface charge and a double layer are also formed on the surface of the PC membrane. So when sols are drawn into the pore channels of PC membranes, two possible scenarios can be envisioned and result in the formation of nanorods and nanotubes, respectively. If the surface charges or zeta potentials of nanoclusters in the sol and the pore surface of the PC membrane are similar, there is no or little attraction force between the nanoclusters in the sol filled inside the pore channel and the pore surface of the PC membrane and, thus, there will be no preferential deposition of solid nanoclusters on the pore surface. Consequently solidification or gelation occurs on the surface of the pore channel and solvent evaporation continuously draws more solid nanoclusters towards the top of the pore, resulting in the formation of solid nanorods. This possibility

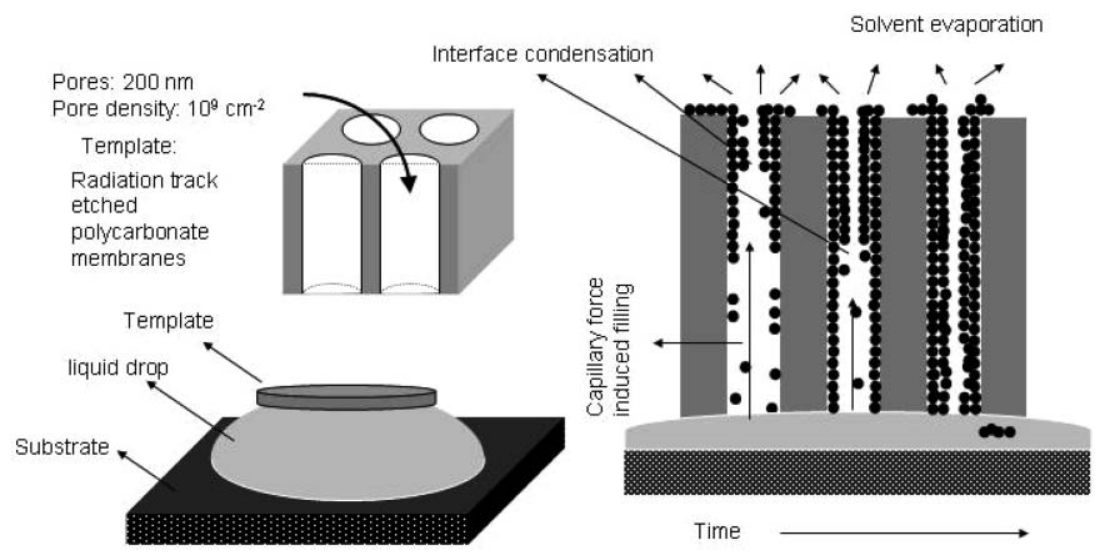

Fig. 2 Schematics of fabrication process of $\mathrm{InVO}_{4}$ nanotube arrays or $\mathrm{InVO}_{4}$-acac nanotube arrays. Top left: three-dimensional view of a polycarbonate membrane; bottom left: set-up for fabrication of nanotube arrays; right: growth process of nanotube arrays. 
has been demonstrated by Takahashi et al. in the formation of $\mathrm{TiO}_{2}-\mathrm{V}_{2} \mathrm{O}_{5}$ composite nanorod arrays by template-based capillary force induced synthesis. ${ }^{32}$

However, if the surface charges and/or zeta potentials of nanoclusters in a sol and the surface of the PC membrane are opposite, there will be an electrostatic attraction force and the nanoclusters will preferentially deposit on the surface of the pore channel resulting in the formation of nanotubes. This phenomenon or observation has also been reported by Martin's group and explained in the same manner. ${ }^{33-35}$ Martin et al. observed the preferential formation of $\mathrm{TiO}_{2}$ nanotubes under conditions where the $\mathrm{TiO}_{2}$ particles are positively charged and the pore walls are assumed to be negatively charged. ${ }^{33}$ It has also been reported by Wang et al. that having a template surface charge of the same sign as the particle charge is necessary for the formation of solid nanorods over hollow nanotubes. ${ }^{36}$ Limmer et al. recently reported similar findings such as the formation of $\mathrm{SiO}_{2}$ nanotubes. ${ }^{37}$ The particle zeta potentials were difficult to obtain in parent sols, therefore, qualitative values were obtained by suspending $\mathrm{InVO}_{4}$ sol powders in aqueous solutions with similar $\mathrm{pH}$ and ionic strength to the parent sol. The zeta potential of $\mathrm{InVO}_{4}$ was thus measured to be $-9.63 \mathrm{mV}$. The $\mathrm{pH}$ of the parent sol was 0.5 . The zeta potential of $\mathrm{PC}$ membrane at this low $\mathrm{pH}$ is positive, as derived from the results reported by Limmer et al. $^{37}$ Therefore, nanotubes will be formed since the zeta potentials of the nanoclusters in the sol and surface of PC membranes are opposite.

Fig. 3 shows the XRD patterns of the $\mathrm{InVO}_{4}$ film and nanotube array and $\mathrm{InVO}_{4}-$ acac nanotube array, all annealed

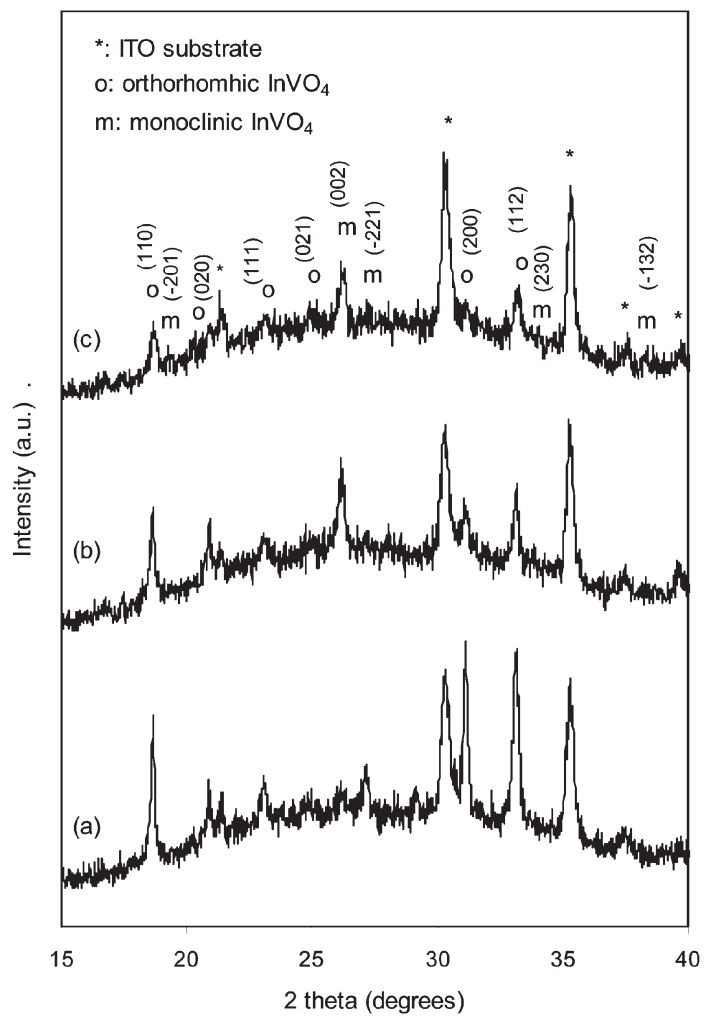

Fig. 3 XRD patterns of (a) $\mathrm{InVO}_{4}$ film, (b) $\mathrm{InVO}_{4}$ nanotube array, and (c) $\mathrm{InVO}_{4}$-acac nanotube array. at $500{ }^{\circ} \mathrm{C}$ for $1 \mathrm{~h}$ in air. All the three samples consist of mixed monoclinic phase (JCPDF 38-1135) and orthorhombic phase (JCPDF 33-0628). The XRD results are in good agreement with those reported in the literature. ${ }^{12}$ For powdered samples of $\mathrm{InVO}_{4}$ synthesized from the dissolution-reprecipitation process and heated for $15 \mathrm{~h}$, the monoclinic phase resulted at $500{ }^{\circ} \mathrm{C}$ and a prevailing orthorhombic phase at $600{ }^{\circ} \mathrm{C},{ }^{1}$ although thermal analysis $\left(10{ }^{\circ} \mathrm{C} \mathrm{min}^{-1}\right)$ shows the crystallization temperatures to be $540{ }^{\circ} \mathrm{C}$ (for the amorphous to monoclinic phase transition) and $700{ }^{\circ} \mathrm{C}$ (for the monoclinic to orthorhombic phase transition). It should be noted that coexistence of monoclinic and orthorhombic phases instead of a pure monoclinic phase is usually found for $\mathrm{InVO}_{4}$ synthesized from the sol-gel route based on vanadium oxoisopropoxide and indium nitrate and heated at $500{ }^{\circ} \mathrm{C}$, as reported by other research groups. ${ }^{12}$ Our separate results show that a pure orthorhombic phase is not achieved until the samples are heated at $600{ }^{\circ} \mathrm{C}$ for prolonged time $\left(2 \mathrm{~h}\right.$ for $\mathrm{InVO}_{4}$ film and $6 \mathrm{~h}$ for $\mathrm{InVO}_{4}$ nanotube array). It can be concluded that the transition temperature between the different phases is higher for $\mathrm{InVO}_{4}$ nanotube arrays than that for $\mathrm{InVO}_{4}$ films, possibly due to the presence and subsequent pyrolysis of polycarbonate membranes. However, heating at such high temperature destroys the ordered nanostructure and no improvement in the electrochemical properties is observed. Therefore, the results and discussion presented in this paper are focused on $\mathrm{InVO}_{4}$ films and nanostructures obtained at $500{ }^{\circ} \mathrm{C}$. By comparing the peak intensities and the breadths of peaks of the two phases in the three samples in Fig. 3, the $\mathrm{InVO}_{4}$ film contains more orthorhombic phase than the nanotube arrays, though the quantitative change is difficult to determine. In addition, the low signal to noise ratio, the low peak intensities, and the broad widths of diffraction peaks in the XRD pattern of $\mathrm{InVO}_{4}$-acac nanotube array all suggest the formation of smaller crystallites, which is consistent with the literature that the addition of acetyl acetone into the sol results in amorphization. $^{12}$

Fig. 4 compares the typical cyclic voltammograms (CVs) (the first cycle) of the $\mathrm{InVO}_{4}$ film, $\mathrm{InVO}_{4}$ nanotube array and $\mathrm{InVO}_{4}$-acac nanotube array within the potential limits of 0.4 to $-2.8 \mathrm{~V} v$ s. $\mathrm{Ag} / \mathrm{Ag}^{+}$using a scan rate of $10 \mathrm{mV} \mathrm{s}{ }^{-1}$. The

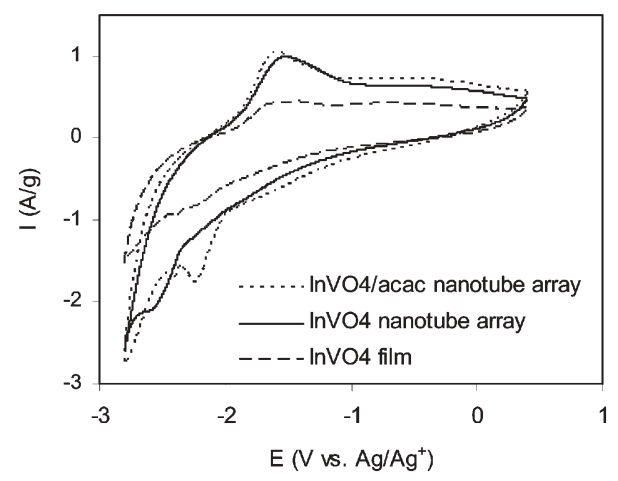

Fig. 4 Cyclic voltammetric (CV) curves of $\mathrm{InVO}_{4}$ films (dashed line), $\mathrm{InVO}_{4}$ nanotube arrays (solid line) and $\mathrm{InVO}_{4}-\mathrm{acac}$ nanotube arrays (dotted line) cycled between the potential limits of 0.4 and $-2.8 \mathrm{~V} v \mathrm{~s}$. $\mathrm{Ag} / \mathrm{Ag}^{+}$using a scan rate of $10 \mathrm{mV} \mathrm{s}^{-1}$. 
shape of the $\mathrm{CV}$ curve of the $\mathrm{InVO}_{4}$ film is similar to those reported in the literature. ${ }^{1,12}$ The $\mathrm{CV}$ curve of the $\mathrm{InVO}_{4}$ film does not have well-expressed peaks except a broad anodic one at $-1.60 \mathrm{~V}$ corresponding to Li-ion extraction. The peaks of the $\mathrm{CV}$ curve of $\mathrm{InVO}_{4}$ nanotube arrays are more distinct, with the cathodic one at $-2.80 \mathrm{~V}$ and an additional broad cathodic peak at $-2.60 \mathrm{~V}$, and a well-defined anodic peak at $-1.48 \mathrm{~V}$. It should be noted that the peak at $-2.8 \mathrm{~V}$ may be part of the true peak possibly with a true peak position at more negative voltage, because the measurement ends at $-2.8 \mathrm{~V}$. The $\mathrm{CV}$ curve of $\mathrm{InVO}_{4}$-acac nanotube arrays is similar to that of $\mathrm{InVO}_{4}$ nanotube arrays except for the shift of the peak positions: the cathodic one from $-2.6 \mathrm{~V}$ to $-2.28 \mathrm{~V}$ and the anodic one from $-1.6 \mathrm{~V}$ to $-1.55 \mathrm{~V}$. The shift of peaks is likely attributable to the material property as the shift of the cathodic peak is $0.32 \mathrm{~V}$, much greater than the shift of $0.05 \mathrm{~V}$ of the anodic peak. However, it is not known exactly what mechanism or mechanisms cause such a shift. Considering the use of the same scan rate in all the $\mathrm{CV}$ measurements presented in Fig. 3, the relatively sharp peaks from the nanotube arrays suggest well defined intercalation/extraction processes, and may be suggestive that intercalation/extraction kinetics are improved as the nanotube arrays provide faster charge/discharge rate due to the higher surface area and shorter diffusion distance as reported earlier in the literature. ${ }^{20}$ However, other possibilities can not be completely ruled out. For example, the $\mathrm{InVO}_{4}$ nanotube arrays may have different, albeit slightly, chemistry or crystallinity due to the initial presence and subsequent pyrolysis of PC membranes.

Fig. 5(a) compares the chronopotentiograms (CPs) (the first cycle) of $\mathrm{InVO}_{4}$ film, $\mathrm{InVO}_{4}$ nanotube array and $\mathrm{InVO}_{4}$-acac nanotube array at a specific current density of $110 \mathrm{~mA} \mathrm{~g}^{-1}$. The CP curves of all three samples have a sloping shape, similar to those reported in the literature. ${ }^{1}$ It is clearly shown that the $\mathrm{InVO}_{4}$-acac nanotube array has the highest charge capacity $\left(790 \mathrm{mAh} \mathrm{g}{ }^{-1}\right.$ ), followed by the $\mathrm{InVO}_{4}$ nanotube array $\left(600 \mathrm{mAh} \mathrm{g}^{-1}\right)$ then the $\mathrm{InVO}_{4}$ film $\left(290 \mathrm{mAh} \mathrm{g}{ }^{-1}\right)$. Fig. 5(b) summarizes and compares the charge capacity as a function of specific current for the $\mathrm{InVO}_{4}$ film, InVO nanotube array and $\mathrm{InVO}_{4}$-acac nanotube array. The $\mathrm{Li}^{+}$ intercalation capacities of both types of nanotube array are higher than those of the $\mathrm{InVO}_{4}$ film, and the $\mathrm{InVO}_{4}-\mathrm{acac}$ nanotube array has the highest charge capacities. Since there exists more orthorhombic phase in the film than in the nanostructure as discussed earlier, and the orthorhombic $\mathrm{InVO}_{4}$ has a larger charge capacity than monoclinic $\mathrm{InVO}_{4}{ }^{1}$ enhanced electrochemical intercalation properties in nanotube arrays are surely attributed to the morphology of the nanostructure and the reduced crystallinity resulted from acetyl addition in the case of $\mathrm{InVO}_{4}$-acac nanotube arrays. Smaller grains possess a large surface area for intercalation surface reaction and a short diffusion distance for $\mathrm{Li}$ ions. The poor crystallinity or partially amorphous nature may also favor enhanced intercalation due to their more open structure. ${ }^{38}$ The mixed phases of orthorhombic and monoclinic $\mathrm{InVO}_{4}$ may also partially contribute to the enhanced charge storage capacity, but experimental results are not available at the moment to support this possible mechanism.
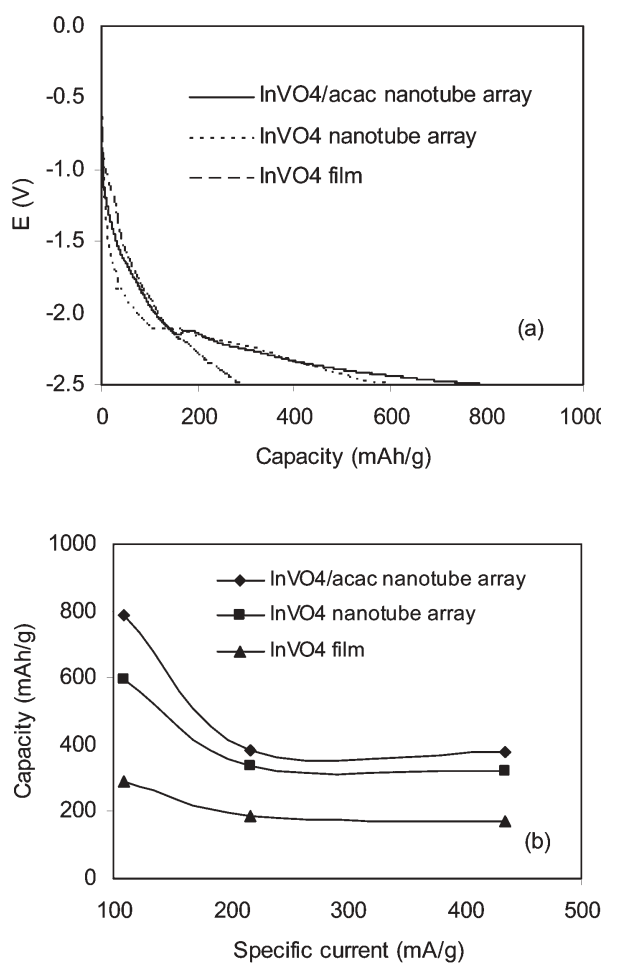

Fig. 5 Charge behavior of $\mathrm{InVO}_{4}$ films (dashed line), $\mathrm{InVO}_{4}$ nanotube arrays (dotted line) and $\mathrm{InVO}_{4}$-acac nanotube arrays (solid line) cycled between the potential limits of 0.4 and $-2.5 \mathrm{~V} v$ s. $\mathrm{Ag} / \mathrm{Ag}^{+}$ under a specific current of $110 \mathrm{~mA} \mathrm{~g}^{-1}$. (b) Capacity (measured from $\mathrm{CP}$ measurements charged to $-2.5 \mathrm{~V}$ vs. $\mathrm{Ag} / \mathrm{Ag}^{+}$) as a function of specific current for $\mathrm{InVO}_{4}$-acac nanotube arrays, $\mathrm{InVO}_{4}$ nanotube arrays and $\mathrm{InVO}_{4}$ films respectively.

It should be noted that the true charge storage capacity in $\mathrm{InVO}_{4}$ nanotube arrays would be far higher than the results described above. The charge capacities of nanotube arrays are actually the nominal results of the combined contribution of nanotube arrays and the films beneath (as schematically illustrated in Fig. 2). At the best, approximately $50 \% \mathrm{InVO}_{4}$ are estimated to be in the form of nanotubes and remaining $50 \%$ form the film beneath. Assuming the $\mathrm{InVO}_{4}$ films beneath possess the same charge capacity as the sol-gel films, the $\mathrm{InVO}_{4}$ nanotube arrays would have the highest charge capacities of $\sim 900 \mathrm{mAh} \mathrm{g}^{-1}$. Similar, a much higher charge storage would be expected for $\mathrm{InVO}_{4}$-acac nanotube arrays $\left(\sim 1200 \mathrm{mAh} \mathrm{g}^{-1}\right)$. The estimation of charge storage capacities may be even higher when considering many nanotubes are broken and lost during the sample handling prior to electrochemical characterization.

Experimental results revealed the nominal cyclic stability of the $\mathrm{InVO}_{4}$ films and nanotube arrays as well as $\mathrm{InVO}_{4}$-acac nanotube arrays is very poor (more than 50\% drop in the second run). To the best of the authors' knowledge, there is no study on the cyclic stability of $\mathrm{InVO}_{4}$ reported in the open literature, though hydrated $\mathrm{InVO}_{4}$ or $\mathrm{InVO}_{4} \cdot n \mathrm{H}_{2} \mathrm{O}$ was reported to possess a very good cyclic stability. ${ }^{1}$ Closer analysis revealed the poor adhesion of $\mathrm{InVO}_{4}$ nanotube arrays and films on the ITO substrates. InVO$_{4}$ films and nanotube arrays would peel off from ITO substrates when subjected to electrochemical intercalation and extraction processes, 
therefore the true cyclic stability of the $\mathrm{InVO}_{4}$ films and nanotube arrays synthesized in the present study is unknown. No appreciable difference in adhesion property was observed when acac was added into $\mathrm{InVO}_{4}$. Regardless of the intrinsic cyclic stability of $\mathrm{InVO}_{4}$, the coexistence of two phases in $\mathrm{InVO}_{4}$ nanostructures in a composite structure would be expected to improve the cycling performance. If the two phases of $\mathrm{InVO}_{4}$ take turns to be electroactive and to intercalate/ deintercalate lithium ions, the inactive phase plays a very important role as a buffer or a matrix that endures the large volumetric stresses related to the other active phase, thereby alleviating the mechanical stress arising from volume expansion/contraction during electrochemical cycling as widely reported in the literature. ${ }^{39}$ For example, the addition of $\mathrm{TiO}_{2}$ has significantly enhanced the cyclic performance of vanadium pentoxide electrodes. ${ }^{40}$ Further well designed and carefully executed experiments are obviously needed to determine the true cyclic stability of $\mathrm{InVO}_{4}$ films and nanostructures.

\section{Conclusions}

In $\mathrm{VO}_{4}-$ acac and $\mathrm{InVO}_{4}$ nanotube arrays were grown by the capillary-enforced template-based method from $\mathrm{InVO}_{4}$ sols with and without acetyl acetone respectively, followed by sintering at $500{ }^{\circ} \mathrm{C}$. These nanotubes covered completely a large area and projected from the surface of the ITO substrate. The nanotubes consist of mixed phases of monoclinic and orthorhombic $\mathrm{InVO}_{4}$, although the crystalline conditions of the $\mathrm{InVO}_{4}$-acac nanotubes were poorer, indicating that addition of acetyl acetone is possible cause of amorphisation. The $\mathrm{Li}^{+}$intercalation capacity and applicable current density of $\mathrm{InVO}_{4}$-acac nanotube arrays are higher than $\mathrm{InVO}_{4}$ nanotube arrays. Both nanotube arrays show better electrochemical performance than films of $\mathrm{InVO}_{4}$ annealed at the same temperature. The highest nominal charge capacity of $\mathrm{InVO}_{4}-$ acac nanotubes has reached $790 \mathrm{mAh} \mathrm{g}^{-1}$. Both morphology and crystalline structure affect the capacity.

\section{Acknowledgements}

This work was supported in part by the National Science Foundation (DMI-0455994) and Air Force Office of Scientific Research (AFOSR-MURI, FA9550-06-1-032). Y. W. acknowledges the Nanotechnology Graduate Research Award from University of Washington Initiative Fund (UIF), the Graduate Fellowship from PNNL-UW Joint Institute for Nanoscience (JIN) and the Ford Motor Company Fellowship. The authors would like to thank Tammy Chou, Peter B. Laxton, and Professor John Berg for their help in zeta potential measurements.

\section{References}

1 S. Denis, E. Baudrin, M. Touboul and J.-M. Tarascon, J. Electrochem. Soc., 1997, 144, 4099.

2 M. Touboul and A. Popot, Rev. Chim. Miner., 1985, 22, 610.
3 B. Orel, U. Opara Krašovec, U. Lavrenčič Štangar and G. Dražič, J. Electrochem. Soc., 2000, 147, 2358.

4 U. Opara Krašovec, B. Orel and R. Reisfeld, Electrochem. SolidState Lett., 1998, 1, 104.

5 U. Opara Krašovec, B. Orel, A. Šurca, N. Bukovec and R. Reisfeld, Solid State Ionics, 1999, 118, 195.

6 M. Touboul, K. Melghit, P. Beńard and D. Louer, J. Solid State Chem., 1995, 118, 93.

7 M. Touboul and P. Toledano, Acta Crystallogr., Sect. B: Struct. Crystallogr. Cryst. Chem., 1980, 36, 240.

8 D. I. Roncaglia, I. L. Botto and E. J. Baran, J. Solid State Chem., 1986, 62, 11

9 M. Touboul, K. Melghit and P. Beńard, Eur. J. Solid State Inorg. Chem., 1994, 31, 151.

10 E. Baudrin, S. Denis, F. Orsini, L. Seguin, M. Touboul and J.-M. Tarascon, J. Mater. Chem., 1999, 9, 101.

11 A. Surca Vuk, U. Opara Krašovec, B. Orel and P. Colomban, J. Electrochem. Soc., 2001, 148, H49.

12 B. Orel, A. Surca Vuk, U. Opara Krašovec and G. Dražič, Electrochim. Acta, 2001, 46, 2059.

13 M. Hirshes, Mater. Sci. Eng., B, 2004, 108, 1.

14 G. Z. Cao, Nanostructures and Nanomaterials, Synthesis, Properties and Applications, Imperial College Press, London, 2004.

15 J. C. Hulteen and C. R. Martin, J. Mater. Chem., 1997, 7, 1075.

16 C. J. Patrissi and C. R. Martin, J. Electrochem. Soc., 1999, 146, 3176.

17 Y. Wang, K. Takahashi, K. H. Lee and G. Z. Cao, Adv. Funct. Mater., 2006, 16, 1133.

18 Y. Wang and G. Z. Cao, Chem. Mater., 2006, 18, 2787.

19 K. Takahashi, S. J. Limmer, Y. Wang and G. Z. Cao, J. Phys. Chem. B, 2004, 108, 9795.

20 K. Takahashi, S. J. Limmer, Y. Wang and G. Z. Cao, Jpn. J. Appl Phys., Part 1, 2005, 44, 662.

21 K. Takahashi, Y. Wang and G. Z. Cao, Appl. Phys. Lett., 2005, 86, 053102 .

22 Y. Wang, K. Takahashi, H. M. Shang and G. Z. Cao, J. Phys. Chem. B, 2005, 109, 3085.

23 K. Takahashi, Y. Wang and G. Z. Cao, J. Phys. Chem. B, 2005, 109, 48

24 G. Z. Cao, J. Phys. Chem. B, 2004, 108, 19921.

25 S. J. Limmer, S. Seraji, M. J. Forbess, Y. Wu, T. P. Chou, C. Nguyen and G. Z. Cao, Adv. Mater., 2001, 13, 1269.

26 S. J. Limmer, S. Seraji, M. J. Forbess, Y. Wu, T. P. Chou, C. Nguyen and G. Z. Cao, Adv. Funct. Mater., 2002, 12, 59.

27 S. J. Limmer and G. Z. Cao, Adv. Mater., 2003, 15, 427.

28 S. J. Limmer, T. P. Chou and G. Z. Cao, J. Mater. Sci., 2004, 39, 895.

29 S. J. Limmer, S. Vince Cruz and G. Z. Cao, Appl. Phys. A, 2004, 79, 421 .

30 S. J. Limmer, T. L. Hubler and G. Z. Cao, J. Sol-Gel Sci. Technol., 2003, 26, 577

31 J. S. Reed, Introduction to Principles of Ceramic Processing, Wiley, New York, 1988.

32 K. Takahashi, Y. Wang, K. Lee and G. Z. Cao, Appl. Phys. A, 2006, 82, 27.

33 B. B. Lakshmi, P. K. Dorhout and C. R. Martin, Chem. Mater., 1997, 9, 857

34 B. B. Lakshmi, C. J. Patrissi and C. R. Martin, Chem. Mater., $1997,9,2544$.

35 J. C. Hulteen and C. R. Martin, J. Mater. Chem., 1997, 7, 1075.

36 Y. C. Wang, I. C. Leu and M. H. Hon, J. Mater. Chem., 2002, 12, 2439.

37 S. J. Limmer, T. P. Chou and G. Z. Cao, J. Sol-Gel Sci. Technol., 2005, 36, 183

38 F. Coustier, S. Passerini and W. H. Smyrl, Solid State Ionics, 1997, 100, 247.

39 J. P. Maranchi, O. I. Velikokhatnyi, M. K. Datta, I. Kim and P. N. Kumta, in Chemical Processing of Ceramics, ed. B. Lee and S. Komarneni, Marcel Dekker, New York, 2005, p. 667.

40 K. Lee, Y. Wang and G. Z. Cao, J. Phys. Chem. B, 2005, 109, 16700 . 